TITLE:

\title{
Chronic myeloid leukemia following treatment for bilateral retinoblastoma
}

\section{$\operatorname{AUTHOR}(S)$ :}

Kamitori, Tatsuya; Umeda, Katsutsugu; Tasaka, Keiji; Ogata, Hideto; Mikami, Takashi; Kato, Itaru; Hiramatsu, Hidefumi; Kondo, Tadakazu; Adachi, Souichi

\section{CITATION:}

Kamitori, Tatsuya ...[et al]. Chronic myeloid leukemia following treatment for bilateral retinoblastoma. Pediatric blood \& cancer 2018, 65(9): e27107.

\section{ISSUE DATE:}

2018-09

URL:

http://hdl.handle.net/2433/254146

\section{RIGHT:}

This is the peer reviewed version of the following article: Kamitori, T., Umeda, K., Tasaka, K., Ogata, H., Mikami, T., Kato, I., Hiramatsu, H., Kondo, T. and Adachi, S. (2018), Chronic myeloid leukemia following treatment for bilateral retinoblastoma. Pediatr Blood Cancer, 65: e27107, which has been published in final form at

https://doi.org/10.1002/pbc.27107. This article may be used for non-commercial purposes in accordance with Wiley Terms and Conditions for Use of Self-Archived Versions.; This is not the published version. Please cite only the published version.; この論文は出版社版でありません。引用の際には出版社版をご確認ご利用ください。 


\section{BRIEF REPORT}

2 Chronic myeloid leukemia following treatment for bilateral retinoblastoma

3 Tatsuya Kamitori ${ }^{1}$, Katsutsugu Umeda ${ }^{1 *}$, Keiji Tasaka ${ }^{1}$, Hideto Ogata ${ }^{1}$, Takashi Mikami ${ }^{1}$, Itaru

4 Kato $^{1}$, Hidefumi Hiramatsu ${ }^{1}$, Tadakazu Kondo ${ }^{2}$, and Souichi Adachi ${ }^{3}$

5

6 Department of Pediatrics ${ }^{1}$ and Hematology ${ }^{2}$, Graduate School of Medicine, Kyoto University,

$7 \quad$ Kyoto, Japan

$8{ }^{3}$ Department of Human Health Sciences, Graduate School of Medicine, Kyoto University, Kyoto,

9 Japan

10

$11 *$ Correspondence to:

12 Katsutsugu Umeda, MD, Department of Pediatrics, Graduate School of Medicine, Kyoto

13 University, 54 Kawahara-cho, Shogoin, Sakyo-ku, Kyoto 606-8507, Japan

14 Tel.: 81-75-751-3290 Fax.: 81-75-752-2361

15 E-mail: umeume@kuhp.kyoto-u.ac.jp

16

17 Text word count: 760

18 Abstract word count: 85 
19 Short running title: CML following treatment for retinoblastoma

20

21 Keywords: retinoblastoma, chronic myeloid leukemia, secondary malignancy, radiation

22 Tables: 1

23 Figures: 0

24 Abbreviations

\begin{tabular}{|l|l|}
\hline CML & Chronic myeloid leukemia \\
\hline RB & Retinoblastoma \\
\hline
\end{tabular}




\section{ABSTRACT}

26 In contrast to their higher incidence of radiation-induced solid tumors, patients with bilateral

27 retinoblastoma $(\mathrm{RB})$ have a low risk of developing therapy-related hematological malignancies. We

28 present the first case of a patient with bilateral RB to develop chronic myeloid leukemia (CML) 15

29 years after multimodality therapy, comprising systemic chemotherapy and external beam radiation

30 to the orbits. We discuss the possible etiology of therapy-related CML in long-term survivors with

31 bilateral RB, although the possibility of de novo CML cannot be completely excluded in the present

case. 


\section{INTRODUCTION}

34 The overall survival rate of patients with intraocular retinoblastoma (RB) exceeds $95 \% .^{1}$ In addition

to conventional treatment modalities, such as enucleation and external beam radiation, systemic

41 germline $R B$ gene mutation, are at significant risk of therapy-related malignancy. ${ }^{5}$ In contrast to

(CML) 15 years after the treatment for bilateral RB.

\section{RESULTS}

A 4-month-old male infant with bilateral RB was successfully treated by enucleation of the right eye, 
53 which he received multiple rounds of systemic chemotherapy, comprising etoposide,

54 cyclophosphamide, and pirarubicin, in combination with intra-arterial and intravitreal injections of melphalan, cryotherapy, and brachytherapy for the left eye. He finally underwent enucleation of the left eye at the age of 10 years, which resulted in long-term remission. The cumulative doses of chemotherapy drugs were as follows: etoposide, 1000 mg/m²; cyclophosphamide, $19.6 \mathrm{~g} / \mathrm{m}^{2}$;

58

60

61 pirarubicin, $310 \mathrm{mg} / \mathrm{m}^{2}$; cisplatin, $90 \mathrm{mg} / \mathrm{m}^{2}$; carboplatin, $750 \mathrm{mg} / \mathrm{m}^{2}$; and vincristine, $51 \mathrm{mg} / \mathrm{m}^{2}$. At 25 years old, laboratory studies during annual follow-up revealed a white blood count count of $32.3 \times 10^{9} / \mathrm{L}$ (myelocytes, $11 \%$; metamyelocytes, 2\%; neutrophils, $69 \%$; basophils, 5\%; monocytes, 4\%; lymphocytes, 9\%), hemoglobin of $14.0 \mathrm{~g} / \mathrm{dL}$, and a platelet count of $218 \times 10^{9} / \mathrm{L}$, although he did not have any clinical symptoms. Biochemical examination revealed marked elevation of lactate dehydrogenase (711 U/L) and uric acid $(7.3 \mathrm{mg} / \mathrm{dL})$. Bone marrow aspiration revealed distinct hypercellularity and a markedly increased myeloid:erythroid ratio (8.43) without increased blasts. Karyotype analysis demonstrated a chromosome translocation, 46, XY, $\mathrm{t}(9 ; 22)(\mathrm{q} 34 ; \mathrm{q} 11.2)$, in all 20 bone marrow cells analyzed. Detection of the major $B C R-A B L$ fusion gene transcripts $\left(2.9 \times 10^{6}\right.$ copies/ $\left.\mu g R N A\right)$ on quantitative polymerase chain reaction led to a diagnosis of CML in chronic phase. Treatment with dasatinib (100 mg/day) normalized the white blood count within 1 month. Bone marrow aspiration after 3 months revealed normocellular marrow, and the quantitative polymerase chain reaction revealed a 4.2 log reduction of the major $B C R-A B L$ fusion gene transcripts $\left(1.7 \times 10^{2}\right.$ copies/ $\left.\mu \mathrm{gRNA}\right)$. Fluorescence in situ hybridization analysis for the $B C R-A B L$ fusion gene and cytogenetic karyotyping results were normal, achieving complete 
cytogenetic response and an optimal response, according to the European LeukemiaNet

74

75

76

77

78

79

80

81

82

83 recommendations. $^{9}$

\section{DISCUSSION}

Patients with bilateral RB have a high risk of developing secondary malignancies, with a cumulative incidence of approximately $30 \%$ at $40-50$ years from diagnosis., 8 About half of secondary malignancies are bone and soft tissue sarcomas, while only $0.5-0.6 \%$ are hematological malignancies (Table 1). ${ }^{6-8}$ Although various types of leukemia and lymphoma have been observed as secondary hematological malignances in patients treated for $\mathrm{RB}$, there are no reports of secondary CML. Moreover, etoposide or alkylator-containig chemotherapy, does not increase the risk of secondary CML in the general population. ${ }^{10}$ Overall, there is no clear reason to assume an association between chemotherapy and development of CML in the present case.

Howard et al. identified 164 patients with secondary CML in 376,835 long-term survivors with breast cancer, representing an excess absolute risk of 2.06 per 100,000 person-years. ${ }^{11}$

\section{Dose-dependent increased risk of radiation-related CML has also been demonstrated in patients} with cervical cancer and ankylosing spondylitis, and in Japanese atomic bomb survivors. ${ }^{12}$ The frequency of secondary CML has decreased over time, possibly due to the recent progress in radiation therapy techniques that allow minimal exposure of the bone marrow to radiation. ${ }^{11}$

Secondary CML is an extremely rare event in patients with $\mathrm{RB}$, considering that approximately $80 \%$ of patients received radiation therapy, ${ }^{6,8}$ which might be explained by the limited field of 
93 radiation to the periorbital bone marrow. Thus, CML in the present case is likely associated with

94 radiation therapy, although the possibility of de novo CML cannot be completely excluded.

95

96 CONFLICT OF INTEREST

97 The authors declare no conflict of interest associated with this manuscript. 


\section{REFERENCES}

99

1. Dimaras H, Kimani K, Dimba EA et al. Retinoblastoma. Lancet. 2012;379:1436-1446.

100

2. Suzuki S, Yamane T, Mohri M, et al. Selective ophthalmic arterial injecsion therapy for intraocular retinoblastoma: the long-term prognosis. Opthalmology. 2011;118:2081-2087.

3. Schueler AO, Flühs D, Anastassiou G, et al. Beta-ray brachytherapy with 106Ru plaques for retinoblastoma. Int J Radiat Oncol Biol Phys. 2006;65:1212-1221.

4. Kaneko A, Suzuki S. Eye-preservation treatment of retinoblastoma with vitreous seeding. Jpn J Clin Oncol. 2003;33:601-607.

5. Kleinerman RA, Yu CL, Little MP, et al. Variation of second cancer risk by family history of retinoblastoma among long-term survivors. J Clin Oncol. 2012;30:950-957.

6. Kleinerman RA, Tucker MA, Tarone RE, et al. Risk of new cancers after radiotherapy in long-term survivors of retinoblastoma: an extended follow-up. $J$ Clin Oncol. 2005;23:2272-2279.

7. MacCarthy A, Bayne AM, Brownbill PA, et al. Second and subsequent tumours among 1927 retinoblastoma patients diagnosed in Britain 1951-2004. Br J Cancer. 2013;108:2455-2463.

8. Marees T, Moll AC, Imhof SM, et al. Risk of second malignancies in survivors of retinoblastoma: more than 40 years of follow-up. J Natl Cancer Inst. 2008;100:1771-1779. management of chronic myeloid leukemia: 2013. Blood. 2013;122:872-884. 
118 myelogenous leukemia? Oncologist. 2008;13:645-654.

119 11. Howard RA, Gilbert ES, Chen BE, et al. Leukemia following breast cancer: an international 120 population-based study of 376,825 women. Breast Cancer Res Treat. 2007;105:359-368.

121 12. Little MP, Weiss HA, Boice JD Jr, et al. Risks of leukemia in Japanese atomic bomb survivors, 122 in women treated for cervical cancer, and in patients treated for ankylosing spondylitis. Radiat 123 Res. 1999;152:280-292. 